\title{
CHRONIC HEART FAILURE CAUSES OSTEOPATHY OR IS OSTEOPATHY A FACTOR IN DEVELOPMENT OF CHRONIC HEART FAILURE?
}

\section{MARIYA MARUSHCHAK ${ }^{1 *}$, INNA KRYNYTSKA ${ }^{2}$, ANNA MIKOLENKO ${ }^{3}$, YURII ANDREYCHYN $^{4}$, YAROSLAV BODNAR $^{3,}$ CHORNOMYDZ IRYNA ${ }^{5}$}

\begin{abstract}
${ }^{1}$ Department of Functional Diagnostics and Clinical Pathophysiology, I. Horbachevsky Ternopil State Medical University, Ukraine. ${ }^{2}$ Department of Clinical Laboratory Diagnostics, I. Horbachevsky Ternopil State Medical University, Ukraine. ${ }^{3}$ Department of Pathoanatomy, Forensic Medicine and Sectional Course, I. Horbachevsky Ternopil State Medical University, Ukraine. ${ }^{4}$ Department of Otorhinolaryngology, Ophthalmology and Neurosurgery, I. Horbachevsky Ternopil State Medical University, ${ }^{5}$ Department of Children Diseases with Pediatric Surgery, I.Horbachevsky Ternopil State Medical University, Ukraine Ukraine.
\end{abstract}

Email: marushchak@tdmu.edu.ua

Received: 02 February 2017, Revised and Accepted: 01 October 2017

ABSTRACT

Objective: As their proportion rises in the aging population, cardiovascular disease and osteoporosis increasingly become significant health problems of the developed world, leading to reduced lifespan and substantial financial burdens, not the least because of complications and comorbidities associated with each disorder. This study investigates bone mineralization in patients with coronary heart disease (CHD) complicated by Stage I chronic heart failure (CHF).

Methods: The study group consisted of 41 patients of both sexes with CHF Stage I against the background of CHD that with no severe comorbidities that could have potentially caused changes in bone tissue. Bone mineral density was measured using dual-energy X-ray densitometry of lumbar region of spine and proximal right femur.

Results: Structural and functional changes in the bone of the lumbar spine were found in $75.9 \%$ of the patients with Stage I CHF caused by CHD. Osteopenia was diagnosed in $64.4 \%$ of the patients, while osteosclerotic bone changes were less frequent and found in $11.5 \%$ of the patients. $75.8 \%$ of the patients had structural and functional changes in the proximal segment of the right femur bone. In men with Stage I CHF against the background of CHD osteopenia was more often diagnosed in the proximal segment of the right femur, while in women it was found in almost equal proportion in the spine and hip.

Conclusions: In both sexes with I Stage CHF against the background of CHD were diagnosed changes in bone mineralization, with osteopenia being the prevailing diagnosis.

Keywords: Coronary disease, Osteopathy, Bone density.

(C) 2018 The Authors. Published by Innovare Academic Sciences Pvt Ltd. This is an open access article under the CC BY license (http://creativecommons. org/licenses/by/4. 0/) DOI: http://dx.doi.org/10.22159/ajpcr.2018.v11i1.17532

\section{INTRODUCTION}

Although structural changes of the spine are primarily connected with aging, so-called diseases of civilization, which predominately include cardiovascular system disorders, increase the pace of osteopathic changes [1]. The prevalence of cardiovascular diseases (CVD) is a global health problem that leads to impaired quality of life and shortens life expectancy [2]. CVD are the most frequent cause of morbidity and mortality not only in developed nations but also in developing nations [3]. CVD, as well as osteoporosis, are high-burden health issues due to their increased incidence with age and significant monetary costs needed for treatment of such patients [4]. Chronic heart failure (CHF) is a syndrome rather than a disease, the cause of which may be structural or functional, or more often than not, both. Whatever be the underlying cause, the cardinal symptoms are dyspnea and fatigue leading to a progressive decrease in exercise capacity [5]. It should be noted that CHF and osteoporosis are often diagnosed in the same patient [6]. The majority of the studies have shown that individuals with CVD have a higher risk of experiencing bone loss and thus greater predisposition to the risk of fracture. On the other hand, there is growing evidence that individuals with low bone mass have a higher mortality for cardiovascular events compared to patients with CVD with normal bone mass [7]. Recent recommendations suggest that elderly patients with low bone mineral density (BMD) require thorough evaluation for possible CVD [8]. Likewise, another study recommends taking into account the possibility of CVD in elderly patients being treated for osteoporosis [9]. Since the treatment of osteoporosis and its complications is a difficult, timeconsuming and not always effective process, currently the predominant approach in dealing with this disease is prevention.

\section{Objectives}

This study aims to investigate bone mineralization in patients with coronary heart disease (CHD) complicated by Stage I CHF.

\section{METHODS}

The study involved 41 patients of both sexes aged from 40 to 70 years with Stage I CHF (according to the classification by Strazhesko, Vasilenko and Lung [1935]) against the background of coronary artery disease. The patients did not have other severe comorbidities that could have caused changes in bone tissue. All study participants were hospitalized patients and had given written consent for their clinical data to be used in the study. All reported research conducted in accordance with the principles set forth in the Helsinki Declaration, 2008.

Diagnosis of coronary artery disease was confirmed using a set of characteristic anamnestic, clinical (typical angina attacks with physical and psycho-emotional stress), biochemical (increased total cholesterol and total lipids levels), and electrocardiography (STsegment depression below the baseline and T-wave inversion) data. 
To corroborate diagnosis, we also used data obtained during a physical examination, such as enlarged to the left heart boundaries, weakened sound of the top tone, stress of the second tone above the aorta, and changes in blood pressure and heart rate.

To verify the diagnosis of heart failure, we used main limiting factors of physical performance and clinical symptoms: Dyspnea, tachycardia, and fatigue after exertion. The final diagnosis of CHF with systolic dysfunction was given based on the results of echocardiography test.

Among the patients included in the study, 23 (56.1\%) were men and 18 $(43.9 \%)$ women. The average age of men was $56.05 \pm 1.68$ years. While their body mass index (BMI) exceeded normal range (set at $<25 \mathrm{~kg} / \mathrm{m}^{2}$ ) and was in the range of uncompensated obesity, $28.25 \pm 0.80 \mathrm{~kg} / \mathrm{m}^{2}$, it was not significantly different from BMI of research groups. The average age of women was $58.11 \pm 2.09$ years, their BMI also exceeded that of

Table 1: BMD of the lumbar spine in patients with CHF Stage I

\begin{tabular}{lllll}
\hline \multirow{2}{*}{ BMD state } & $\begin{array}{l}\text { Vertebra } \\
\text { number }\end{array}$ & \multicolumn{2}{l}{ BMD, g/cm } & \multirow{2}{*}{ p-value } \\
\cline { 3 - 4 } & & Men & Women & \\
\hline Osteopenia & $\mathrm{L}_{1}$ & $1.10 \pm 0.03$ & $0.93 \pm 0.02$ & $<0.001$ \\
syndrome & & & & \\
Men: $\mathrm{n}=7$, & & & & \\
Women, $\mathrm{n}=14$ & & & & \\
& $\mathrm{~L}_{2}$ & $1.16 \pm 0.02$ & $1.01 \pm 0.02$ & $<0.001$ \\
& $\mathrm{~L}_{3}$ & $1.14 \pm 0.04$ & $1.07 \pm 0.02$ & $>0.05$ \\
& $\mathrm{~L}_{4}$ & $1.08 \pm 0.02$ & $1.02 \pm 0.03$ & $>0.05$ \\
Normal & $\mathrm{L}_{1}$ & $1.14 \pm 0.02$ & $1.13 \pm 0.00$ & - \\
Men: $\mathrm{n}=10$, & & & & \\
Women: $\mathrm{n}=1$ & & & & \\
& $\mathrm{~L}_{2}$ & $1.24 \pm 0.02$ & $1.10 \pm 0.00$ & - \\
& $\mathrm{L}_{3}$ & $1.23 \pm 0.02$ & $1.17 \pm 0.00$ & - \\
Increased & $\mathrm{L}_{4}$ & $1.27 \pm 0.02$ & $1.21 \pm 0.00$ & $<0.001$ \\
Men: $\mathrm{n}=6$, & $\mathrm{L}_{1}$ & $1.17 \pm 0.03$ & $1.30 \pm 0.17$ & $>0.05$ \\
Women: $\mathrm{n}=4$ & $\mathrm{~L}_{2}$ & $1.31 \pm 0.03$ & $1.38 \pm 0.10$ & $>0.05$ \\
& $\mathrm{~L}_{3}$ & $1.37 \pm 0.02$ & $1.45 \pm 0.12$ & $>0.05$ \\
& $\mathrm{~L}_{4}$ & $1.33 \pm 0.03$ & $1.44 \pm 0.05$ & $>0.05$ \\
\hline
\end{tabular}

$\mathrm{p}$-value indicates significant difference between the sexes, BMD: Bone mineral density, CHF: Chronic heart failure the control group by $16 \%$ and was in the range of uncompensated obesity, $28.08 \pm 1.20 \mathrm{~kg} / \mathrm{m}^{2}$. Clinical characteristics of the patients in the experimental group were as follows: The disease duration ranged from 2 to 5 years, the underlying disorders mainly were postmyocardial infarction cardiosclerosis and stable angina.

During the initial assessment, we found no significant statistical differences anthropometric characteristics such as age, BMI, and length of the between male and female patients, thus for the purposes of subsequent statistical analysis, we directly compared these two groups.

DXA is widely used for measuring BMD because of its recognized precision [10]. The method utilizes two measurements, T-score and Z-score. The first one is calculated when the patient's BMD is subtracted from mean BMD of a population of healthy young adults, matched. The T-score is calculated as a number of SDs the patient's measured BMD is above or below the mean for the population of healthy 30-year adults, matched for sex and ethnicity. The Z-score is expressed in units of the population SD, but instead of comparing the patient's BMD to the mean of the young adult population, it is compared with the mean BMD of a healthy population matched for age, sex, and ethnicity. In this study, we evaluated the scores according to the WHO guidelines (WHO, Geneva, 1994): BMD $>1.2 \mathrm{~g} / \mathrm{sm}^{2}$ is classified as osteosclerosis; a T-score $\geq-1$ is regarded as normal and T-score between -2.5 and -1 is classified as osteopenia [11].

The control population samples were selected from a densitometric database of healthy individuals maintained at the medical diagnostic center of Ternopil State Medical University and designated as young adults and age-matched groups $[12,13]$.

The results were analyzed using Statistica 7.0 software and presented as mean with standard deviations. To evaluate the distribution of the character together by sampling data, we have used Lilliefors and Kolmogorov - Smirnov tests. The differences between all groups were determined using one-way ANOVA, followed by post hoc least significant difference test. $\mathrm{p}<0.05$ was considered statistically significant.

\section{RESULTS}

Densitometry analysis of lumbar segment in the second group of patients with Stage I CHF showed that in men normal BMD was

Table 2: BMD of the lumbar spine in patients with CHF Stage I and its departure from bone mass density of healthy young adults (young adult) group

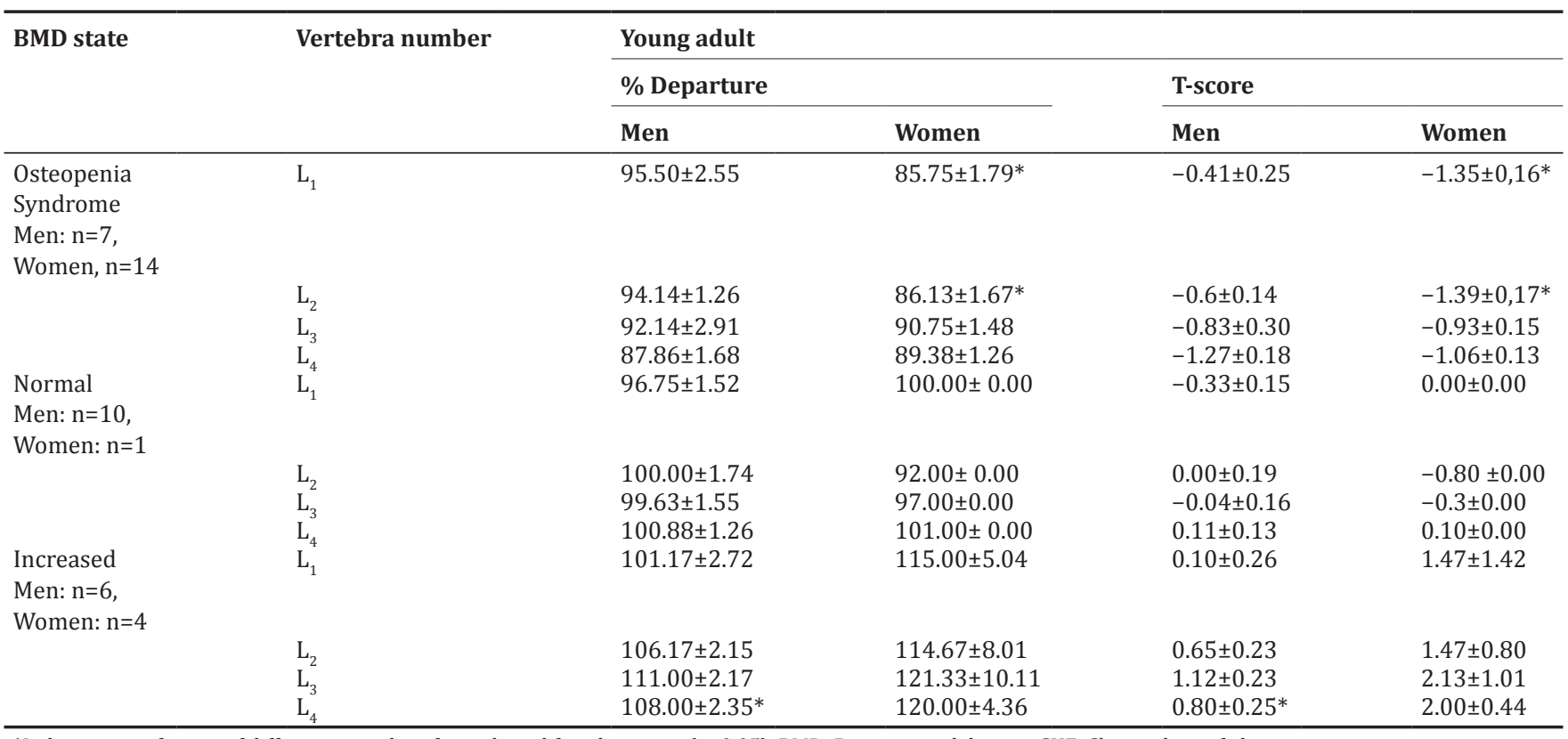

*Indicates significance of difference in values for male and female groups ( $p<0.05)$, BMD: Bone mineral density, CHF: Chronic heart failure 
predominate (43.5\%), while osteopenia and osteosclerotic bone changes were diagnosed with almost equal frequency. In women, 77.8\% had osteopenia and $22.2 \%$ osteosclerotic bone changes (Tables 1-3). It should be noted that in females diagnosed with osteopenia the indicators of BMD were significantly lower than in men at $\mathrm{L}_{1}$ and $\mathrm{L}_{2}$, whereas in patients with increased mineralization BMD changed in the same way in both sexes in all studied vertebrae (Table 1).

A comparative analysis of indicators of the detected peak BMD to that in young healthy subjects in Table 2 shows that compared with men, in women with osteopenia the mineral content reduction in the first two lumbar vertebrae is more pronounced, while BMD is significantly increased in cases of osteosclerosis at $\mathrm{L}_{4}$. Because we found no CHF Stage I female patients with preserved BMD, it was not possible to compare male and female BMD indicators in this group.

Age-matched BMD measurements (\% departure and Z-score) in men diagnosed with osteopenia do not differ from their BMD scores relative to young healthy adults ( $p>0.05)$, while in women scores calculated in relation to the age-matched were higher than the ones to young adult: At $\mathrm{L}_{1}$ by 1.67 times; $\mathrm{L} 2$ by 1.96 times; L3 by 1.46 times; and $\mathrm{L}_{4}$ by 1.68 times.

BMD data of the right proximal femur (Table 4) show a large number of osteopenia cases (61.8\%) compared to those of preserved BMD (38.2\%), indicating more pronounced changes of thigh bone tissue as opposed to the lumbar spine. Densitograms of the patients with low mineralization show in $100 \%$ of the cases osteopenia in Ward's triangle $(\Delta)$, in $30.77 \%$ of the cases osteopenia of the femoral neck, and in $7.69 \%$ of the cases general osteopenia. In men, we diagnosed no bone changes in the greater trochanter. Assessing the osteopenic syndrome, we found significantly lower $(\mathrm{p}<0.05)$ rates of BMD relative to the young adult group (\% departure and T-score) in all surveyed areas compared with normal bone tissue in male patients with CHF Stage I. The indicators of bone tissue mineralization of the same patients relative to the agematched group (\% departure and Z-score) were also lower $(\mathrm{p}<0.05)$ in the femoral neck, $\Delta$ Ward section and the proximal femur.

Comparative analysis of the structural and functional condition of the hip bone in female patients with CHF Stage I show the prevalence of bone demineralization. Various degrees of osteopenia were found in $61 \%$ of the patients, while $39 \%$ exhibited preserved BMD. When compared to the young adult reference group, right femur BMD values in these women show bone density decrease in the femoral neck, Ward's triangle and the greater trochanter as measured by both \% departure and T-score. At the same time, the ratio of the female patients' BMD to that of the age-matched group was significantly higher than the ratio of the patients' BMD to the young adult group (Table 5).

Given the large number of patients with CHF Stage I diagnosed with osteoporosis of proximal femur, we analyzed the extent of osteopenia. Among the 24 patients, Stage 1 osteoporosis was diagnosed: In the neck,

Table 3: BMD of the lumbar spine in patients with CHF Stage I and its departure from bone mass density of age-matched group

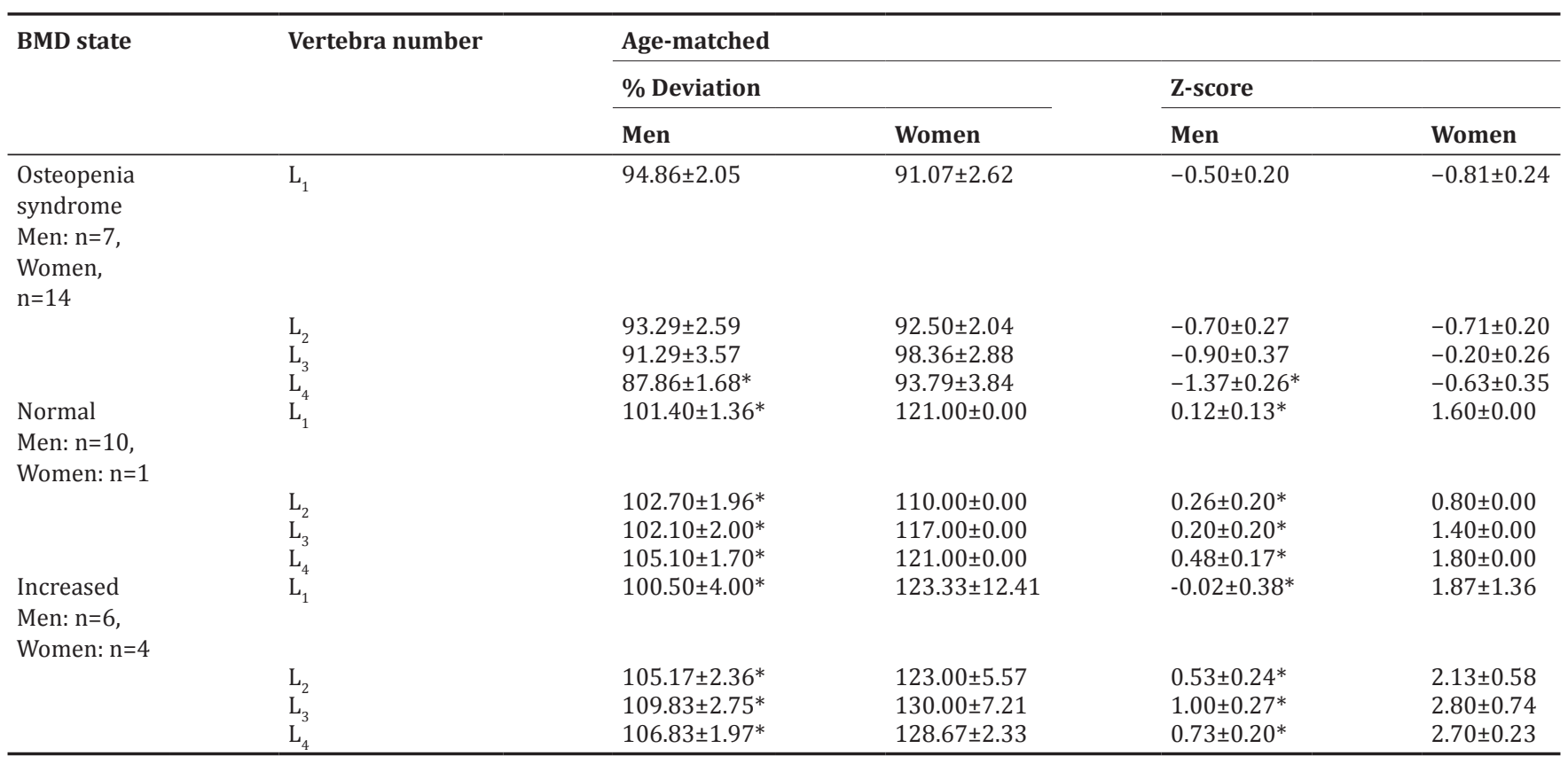

*Indicates significance of difference in values for male and female groups ( $<<0.05$ ), BMD: Bone mineral density, CHF: Chronic heart failure

Table 4: BMD of the proximal right femur in male patients with CHF Stage I

\begin{tabular}{|c|c|c|c|c|c|c|}
\hline \multirow[t]{2}{*}{ BMD state } & \multirow[t]{2}{*}{ Area of femur } & \multirow[t]{2}{*}{ BMD, $\mathrm{g} / \mathrm{sm}^{2}$} & \multicolumn{2}{|l|}{ Young adult } & \multicolumn{2}{|l|}{ Age-matched } \\
\hline & & & \% Departure & T-score & \% Departure & Z-score \\
\hline \multirow{4}{*}{ Osteopenia syndrome $(n=13)$} & Neck & $0.95 \pm 0.02 *$ & $91.38 \pm 1.26$ & $-0.73 \pm 0.10$ & $97.54 \pm 1.63^{*}$ & $-0.20 \pm 0.13^{*}$ \\
\hline & Ward's triangle & $0.76 \pm 0.02^{*}$ & $68.50 \pm 0.49^{*}$ & $-1.61 \pm 0.12^{*}$ & $92.85 \pm 2.24 *$ & $-0.48 \pm 0.14^{*}$ \\
\hline & Troch & $0.92 \pm 0.02 *$ & $98.00 \pm 1.40^{*}$ & $-0.14 \pm 0.12^{*}$ & $101.46 \pm 2.30 *$ & $0.12 \pm 0.19^{*}$ \\
\hline & Total & $1.03 \pm 0.01^{*}$ & $95.63 \pm 0.63^{*}$ & $-0.34 \pm 0.05^{*}$ & $100.15 \pm 1.59^{*}$ & $-0.01 \pm 0.12^{*}$ \\
\hline \multirow{4}{*}{ Preserved $(n=8)$} & Neck & $1.05 \pm 0.01$ & $100.37 \pm 5.40$ & $0.05 \pm 0.44$ & $107.12 \pm 3.55$ & $0.55 \pm 0.28$ \\
\hline & Wards & $0,98 \pm 0.07$ & $102.34 \pm 6.81$ & $0.03 \pm 0.37$ & $117.37 \pm 5.63$ & $1.09 \pm 0.35$ \\
\hline & Troch & $1.02 \pm 0.03$ & $114.50 \pm 5.39$ & $1.05 \pm 0.28$ & $114.32 \pm 3.61$ & $1.11 \pm 0.24$ \\
\hline & Total & $1.16 \pm 0.04$ & $103.86 \pm 5.28$ & $0.77 \pm 0.40$ & $113.00 \pm 2.94$ & $0.95 \pm 0.23$ \\
\hline
\end{tabular}

*Indicates significant difference between patients with normal and reduced BMD ( $<<0.05)$, BMD: Bone mineral density, CHF: Chronic heart failure 
Table 5: BMD of the proximal right femur in female patients with CHF Stage I

\begin{tabular}{|c|c|c|c|c|c|c|}
\hline \multirow[t]{2}{*}{ BMD state } & \multirow[t]{2}{*}{ Area of femur } & \multirow[t]{2}{*}{ BMD, $\mathbf{r} / \mathbf{C M}^{2}$} & \multicolumn{2}{|l|}{ Young adult } & \multicolumn{2}{|l|}{ Age-matched } \\
\hline & & & $\%$ & $\mathbf{T}$ & $\%$ & $\mathbf{Z}$ \\
\hline \multirow[t]{3}{*}{ Osteopenia syndrome $(n=13)$} & Neck & $0.89 \pm 0.02^{*}$ & $90.38 \pm 1.65^{*}$ & $-0.80 \pm 0.13^{*}$ & $100.45 \pm 2.18^{*}$ & $0.03 \pm 0.16^{*}$ \\
\hline & Troch & $0.76 \pm 0.03^{*}$ & $97.63 \pm 3.20^{*}$ & $-0.15 \pm 0.23^{*}$ & $100.30 \pm 3.24^{*}$ & $0.01 \pm 0.22^{*}$ \\
\hline & Total & $0.95 \pm 0.03$ & $96.00 \pm 2.31^{*}$ & $-0.34 \pm 0.18$ & $102.45 \pm 3.05^{*}$ & $0.16 \pm 0.21^{*}$ \\
\hline \multirow[t]{4}{*}{ Preserved $(n=8)$} & Neck & $1.09 \pm 0.10$ & $112.25 \pm 9.46$ & $1.00 \pm 0.78$ & $121.25 \pm 7.44$ & $1.59 \pm 0.66$ \\
\hline & Wards & $0.95 \pm 0.08$ & $103.50 \pm 8.15$ & $0.29 \pm 0.57$ & $123.95 \pm 7.97$ & $1.36 \pm 0.51$ \\
\hline & Troch & $0.97 \pm 0.10$ & $118.54 \pm 9.77$ & $1.60 \pm 0.82$ & $121.96 \pm 7.65$ & $1.54 \pm 0.58$ \\
\hline & Total & $1.11 \pm 0.08$ & $109.50 \pm 5.65$ & $0.55 \pm 0.50$ & $116.87 \pm 4.65$ & $1.21 \pm 0.35$ \\
\hline
\end{tabular}

*Indicates significant difference between patients with normal and reduced BMD ( $\mathrm{p}<0.05)$, BMD: Bone mineral density, CHF: Chronic heart failure

in 5 individuals; $\Delta$ Ward, 12; the greater trochanter, 2; and throughout the proximal femur, in 3. Stage 2 osteoporosis was diagnosed in the neck of femur of 2 patients and $\Delta$ Ward of 6; while Stage 3 osteoporosis was diagnosed in $\Delta$ Ward noted of 4 patients. Patients with primary osteopenia had BMD in the femoral neck $(0.88 \pm 0.02) \mathrm{g} / \mathrm{sm}^{2}$, in $\Delta$ Ward - $(0.78 \pm 0.01) \mathrm{g} / \mathrm{sm}^{2}$, in the trochanter area $(0.66 \pm 0.01) \mathrm{g} / \mathrm{sm}^{2}$, and overall $(0.88 \pm 0.03) \mathrm{g} / \mathrm{sm}^{2}$.

Comparison of T-scores showed that the most significant BMD changes were observed in $\Delta$ Ward $(-1.29 \pm 0.04)$, followed by the neck $(-1.24 \pm 0.05)$, greater trochanter $(-1.20 \pm 0.00)$, and in the total proximal area of the femur $(-1.17 \pm 0.07)$. In Stage 2 osteoporosis, BMD of $\Delta$ Ward $(0.71 \pm 0.01) \mathrm{g} / \mathrm{cm}^{2}$ was significantly lower than the same indicator in the neck of the femur $(0.82 \pm 0.04) \mathrm{g} / \mathrm{cm}^{2}$.

Decrease in bone mineralization was reflected in decreased T-score, which in the area of $\Delta$ Ward was $10.6 \%$ lower than in the neck of the femur. Stage 3 osteoporosis was diagnosed in 4 patients; their BMD was $(0.65 \pm 0.02) \mathrm{g} / \mathrm{sm}^{2}$, and the T-score was $(-2.28 \pm 0.09)$. The results indicate that in men with CHF Stage I osteopenia syndrome is more often diagnosed in the proximal right femur, while in women it is diagnosed almost equally often in the spine and hip.

\section{DISCUSSION}

Studies point to the connection of CVD with decreased BMD $[14,15]$. CVD and osteoporosis are major causes of morbidity, mortality, and disability.

Myocardium's ability to contract is an important factor determining adequate blood circulation in organs and tissues. Isotropic function of the heart depends on the interaction of cytosol calcium with contractile proteins. Increased interaction may be due to increasing calcium levels in cardiomyocytes during the systole or increased sensitivity of the protein structures to calcium [16]. In this study, we aimed to show the relationship of CHF with pathological changes in bone tissue that are generally not caused by the usual risk factors.

There are well-characterized biochemical changes observed during CHF, including reduced activity of enzymes that regulate calcium homeostasis; inhibited calcium ATPase in the sarcoplasmic reticulum; and increased activity of sarcolemmal sodium-calcium exchange [17]. These changes are accompanied by shifts in calcium homeostasis, with decreased diastolic capture of calcium in the sarcoplasmic reticulum, followed by decrease in calcium release during the next systole, resulting in hypercontractivity of the myocardium. Results of this study suggest that during CHF advance the levels of calcium and phosphorus in the blood may be supported at the expense of the destruction of the bone tissue, which, in some cases, can initiate development of osteoporosis. Therefore, we believe that CVD is one of the factors that reduce $\mathrm{BMD}$, while bone demineralization, in turn, complicates the course of CHF pathology.

As a result, structural and functional changes in the bone tissue of the lumbar spine were found in $75.9 \%$ of patients with Stage 1 of $\mathrm{CHF}$ caused by ischemic heart disease: $64.4 \%$ of patients had osteopenic syndrome, and the rest, $11.5 \%$, osteosclerotic changes. In $75.8 \%$ of CHF patients, we found structural and functional changes in the bone tissue of proximal right femur. In men with CHF Stage I against the background of CHD, osteopenic syndrome was more often diagnosed in the proximal right femur, while in women in almost equal measure in the spine and hip.

\section{ACKNOWLEDGMENTS}

The author is grateful to PhD Inna Birchenko for revision of the English text.

\section{AUTHORS CONTRIBUTION}

Conception, design, data analysis and interpretation, manuscript draft and critical review, final approval of the manuscript.

\section{CONFLICTS OF INTERESTS}

The author declares that there is no potential conflict of interest.

\section{REFERENCES}

1. Wójcik G, Sokołowska B, Borzęcki A. Concentration of some amino acids in blood plasma and study results of lumbosacral bone system computer tomography. Health Probl Civiliz 2015;3:5-11.

2. Nur'amin HW, Dwiprahasto I, Kristin E. Effectiveness of ticagrelor compared to clopidogrel in reducing the risk of major adverse cardiovascular events in patients with coronary heart disease after percutaneous coronary intervention. Int J Pharm Pharm Sci 2017;9:178-83.

3. Devadawson C, Jayasinghe C, Ramiah S, Kanagasing A. Amassessment of lipid profile and atherogenic indices for cardiovascular disease risk based on different fish consumption habits. Asian J Pharm Clin Res 2016;9:156-60.

4. Warburton DE, Nicol CW, Gatto SN, Bredin SS. Cardiovascular disease and osteoporosis: Balancing risk management. Vasc Health Risk Manag 2007;3:673-89.

5. Pai S, Kamath P, Sacubitril A. New paradigm in heart failure. Asian J Pharm Clin Res 2016;9:37-40.

6. Schulz E, Arfai K, Liu X, Sayre J, Gilsanz V. Aortic calcification and the risk of osteoporosis and fractures. J Clin Endocrinol Metab 2004;89:4246-53.

7. Krynytska I, Marushchak M, Zaets T, Savchenko I, Habor H. Investigation of bone mineralization in patients with coronary heart disease complicated by chronic heart failure, stage II-A. Georgian Med News 2017;43-8.

8. Yesil Y, Ulger Z, Halil M, Halaçli B, Yavuz BB, Yesil NK, et al. Coexistence of osteoporosis $(\mathrm{OP})$ and coronary artery disease (CAD) in the elderly: It is not just a by chance event. Arch Gerontol Geriatr 2012;54:473-6.

9. Paccou J, Edwards MH, Ward KA, Jameson KA, Moss CL, Harvey NC, et al. Ischemic heart disease is associated with lower cortical volumetric bone mineral density of distal radius. Osteoporos Int 2015;26:1893-901.

10. Cummings SR, Palermo L, Browner W, Marcus R, Wallace R, Pearson J, et al. Monitoring osteoporosis therapy with bone densitometry: Misleading changes and regression to the mean. Fracture intervention trial research group. JAMA 2000;283:1318-21. 
11. Kovalchuk LY. Problems Osteoporosis. Ternopil: Ukrmedknyha; 2002. p. 446.

12. Smiyan SI, Masik OM, Zhulkevych IV, Korylchuk NI, Babinets LS. Indicators of bone mineral density in healthy residents of Ukraine (Ternopil region) the results of dual energy X-ray densitometry. Post I: the female population. Probl Osteol 2000;3:9-16.

13. Smiyan SI, Masik OM, Zhulkevych IV. Indicators of bone mineral density of healthy men on the results of dual energy X-ray densitometry. Probl Osteol 2002;2:9-16.

14. Mussolino ME, Madans JH, Gillum RF. Bone mineral density and mortality in women and men: The NHANES I epidemiologic follow-up study. Ann Epidemiol 2003;13:692-7.

15. Trivedi DP, Khaw KT. Bone mineral density at the hip predicts mortality in elderly men. Osteoporos Int 2001;12:259-65.

16. Bristow MR. beta-adrenergic receptor blockade in chronic heart failure. Circulation 2000;101:558-69.

17. Grados F, Brazier M, Kamel S, Duver S, Heurtebize N, Maamer M, et al. Effects on bone mineral density of calcium and vitamin $\mathrm{D}$ supplementation in elderly women with vitamin $\mathrm{D}$ deficiency. Joint Bone Spine 2003;70:203-8. 